\title{
Modeling Salmonella Typhimurium Inactivation in Dry-Fermented Sausages: Previous Habituation in the Food Matrix Undermines UV-C Decontamination Efficacy
}

\author{
Yhan S. Mutz'1,2,3, Denes K. A. Rosario ${ }^{1,2,3}$, Patricia C. Bernardes 4 , \\ Vania M. F. Paschoalin ${ }^{1}$ and Carlos A. Conte-Junior ${ }^{1,2,3,5 *}$ \\ 1 Post Graduate Program in Food Science, Institute of Chemistry, Federal University of Rio de Janeiro, Rio de Janeiro, Brazil, \\ ${ }^{2}$ Analytical and Molecular Laboratory Center, Faculty of Veterinary Medicine, Fluminense Federal University, Niterói, Brazil, \\ ${ }^{3}$ Center for Food Analysis, Technological Development Support Laboratory (LADETEC), Federal University of Rio de Janeiro, \\ Rio de Janeiro, Brazil, ${ }^{4}$ Department of Food Engineering, Federal University of Espirito Santo, Alto Universitário, Alegre, \\ Brazil, ${ }^{5}$ National Institute of Health Quality Control, Oswaldo Cruz Foundation, Rio de Janeiro, Brazil
}

OPEN ACCESS

Edited by: Javier Carballo,

University of Vigo, Spain

Reviewed by:

Krzysztof Skowron,

Nicolaus Copernicus University

in Toruń, Poland

Byron Brehm-Stecher,

lowa State University, United States

${ }^{*}$ Correspondence:

Carlos A. Conte-Junior conte@iq.ufrj.br

Specialty section:

This article was submitted to

Food Microbiology,

a section of the journal

Frontiers in Microbiology

Received: 10 January 2020

Accepted: 18 March 2020

Published: 08 April 2020

Citation:

Mutz YS, Rosario DKA

Bernardes $P C$, Paschoalin VMF and

Conte-Junior CA (2020) Modeling

Salmonella Typhimurium Inactivation

in Dry-Fermented Sausages: Previous

Habituation in the Food Matrix

Undermines UV-C Decontamination

Efficacy. Front. Microbiol. 11:591.

doi: 10.3389/fmicb.2020.00591
The effects of previous Salmonella Typhimurium habituation to an Italian-style salami concerning pathogen resistance against ultraviolet-C light (UV-C) treatment were modeled in order to establish treatment feasibility for the decontamination of dryfermented sausage. S. Typhimurium following $24 \mathrm{~h}$ habituation in fermented sausage (habituated cells) or non-habituation (non-habituated cells) were exposed to increasing UV-C radiation treatment times. The Weibull model was the best fit for describing $S$. Typhimurium UV-C inactivation. Heterogeneity in UV-C treatment susceptibilities within the $S$. Typhimurium population was observed, revealing intrinsic persistence in a subpopulation. UV-C radiation up to $1.50 \mathrm{~J} / \mathrm{cm}^{2}$ was a feasible treatment for dry-fermented sausage decontamination, as the matrices retained instrumental color and lipid oxidation physiochemical characteristics. However, habituation in the sausage matrix led to a 14fold increase in the UV-C dose required to achieve the first logarithm reduction ( $\delta$ value) in S. Typhimurium population. The results indicate that, although UV-C radiation might be considered an efficient method for dry-fermented sausage decontamination, effective doses should be reconsidered in order to reach desirable food safety parameters while preserving matrix quality.

Keywords: inactivation kinetics, Weibull model, dry-cured meat, non-thermal technology, food safety, preservation of sensory characteristics

\section{INTRODUCTION}

Ready-to-eat meat products may pose a safety risk for consumers, due to contamination by foodborne pathogens, such as Salmonella, during either the pre or post-processing stages (Mutz et al., 2019, 2020). Salmonella enterica is a foodborne pathogen able to contaminate a wide range of foods from both vegetal and animal origins, raising public health authority concerns worldwide (Ferrari et al., 2019). Salmonellosis is the second most reported cause of gastrointestinal infection 
in humans, accounting for $29 \%$ of total foodborne outbreaks in United States and $30.7 \%$ in the European Union (Center for Disease Control and Prevention [CDC], 2019; European Food Safety Authority [EFSA] and European Centre for Disease Prevention, and Control [ECDC], 2019). Salmonella Typhimurium is the most frequent serovar concerning animalbased food contamination (Ferrari et al., 2019) and the second serovar involved in outbreaks (Gossner et al., 2012; Scavia et al., 2013; Andreoli et al., 2017).

Physicochemical matrix characteristics such as low water activity, a moderately acidic $\mathrm{pH}$ and indigenous competitive microbial population inherent to dry-fermented sausages are natural hurdles for microbial growth (Leistner and Gorris, 1995). The harmful combination effects of these sublethal stresses on bacterial cells is the pillar to guarantee the safety of drycured meat products. However, even traditional manufacturing process, such as those well established and used for centuries in the preparation of Italian salami, a dry-fermented sausage, cannot ensure the absence of Salmonella spp. contamination (Bonardi et al., 2017). As no specific step is included along the manufacturing process of dry-fermented meat products for pathogen elimination, the abiotic stresses exerted by the food matrix can transform pre-existent foodborne pathogens into more persistent and even more virulent organisms (Mutz et al., 2020).

Several studies on different non-thermal alternative technologies able to kill pathogens and maintain the safety of dry-fermented sausages have been performed (Cabeza et al., 2009; Chun et al., 2009; Porto-Fett et al., 2010; Ganan et al., 2013; Rosario et al., 2019). The use of non-thermal technologies to guarantee the safety of dry-fermented sausages has been addressed, since high temperatures may lead to detrimental effects on the sensory characteristics of these meat products. Among the different non-thermal technologies, ultraviolet-C light (UV-C) is noteworthy, as it is considered environmental-friendly, displaying low costs and being easily applied to the food industry (Koutchma, 2009). UV-C treatment acts at a superficial level, limiting the practical application of this technology to sanitize meat products. However, this is not a drawback for the decontamination of sliced readyto-eat products, since post-processing contamination occurs mostly at the product surface, during handling, slicing, and packing, and UV-C may be applied on both sides of the slices to guarantee efficient sanitization (Ganan et al., 2013). Recently, several food matrix characteristics that may impact the efficacy of UV-C microorganism inactivation have been emphasized (Gayán et al., 2011; Geveke et al., 2011; Canto et al., 2018; Monteiro et al., 2018; Castro et al., 2019). However, matrix habituation effects exerted on foodborne pathogens is a novel aspect which has not yet been adequately addressed.

In this context, the aim of the present study was to evaluate the efficiency of UV-C light on the inactivation of Salmonella Typhimurium habituated to the stress conditions that take place during pathogen long-term exposure to the dry-fermented sausage matrix. The feasibility of UV-C light application on the decontamination of dry-fermented sausages was also addressed by evaluating sausage quality following Salmonella inactivation treatment.

\section{MATERIALS AND METHODS}

\section{Dry-Fermented Sausages}

Dry-fermented sausages, a type of salami, were purchased at a local market in the municipality of Niterói, RJ (Brazil) and stored under refrigeration following manufacturer recommendations until analysis. The declared sausage composition was as follows: pork meat, skin milk powder, fat (lard), salt, white wine, sugar, mix of spices (mostly black pepper), sodium ascorbate, and sodium nitrate, containing an average $3.8 \%$ of carbohydrates, $25 \%$ of proteins and $32 \%$ fat. Samples presented an average $\mathrm{pH}$ of $5.4 \pm 0.2$ and $\mathrm{a}_{\mathrm{w}}$ of $0.85 \pm 0.1$. Sausages were cut into $1.0 \mathrm{~mm}$ thick slices using a meat slicer (Arbel ${ }^{\circledR}$ Ftd 178 MC/MC-X 3.0, SP, Brazil) using blades previously disinfected with $70 \%$ alcohol and rinsed with sterile distilled water.

\section{Bacterial Culture Conditions}

Salmonella enterica serovar Typhimurium ATCC 14028 stock cultures were maintained in brain heart infusion broth (BHI) $\left(\mathrm{BD}^{\circledR}, \mathrm{NJ}\right.$, United States) containing 20\% (v/v) glycerol at $80 \pm 1^{\circ} \mathrm{C}$. Cultures were also grown at $4^{\circ} \mathrm{C}$ in Hektoen enteric agar (HE) (Liofilchem ${ }^{\circledR}$, Teramo, Italy) and renewed monthly. Working cultures were obtained by transferring one single colony displaying a characteristic morphology from the $\mathrm{HE}$ agar to $10 \mathrm{~mL}$ of BHI broth. Cells were cultured overnight at $37 \pm 1^{\circ} \mathrm{C}$ until reaching the late stationary growth phase, at a cellular density of approximately $10^{8} \mathrm{CFU} / \mathrm{mL}$, confirmed by $\mathrm{HE}$ agar counts. Plating was performed using a Spiral Plater Eddy Jet 2 (IUL Instruments, Barcelona, ESP) and enumeration was carried out using an electronic Flash \& go counter (IUL instruments).

\section{Exogenous Sausage Contamination and Salmonella Typhimurium Habituation to the Dry-Fermented Sausage Matrix}

Sliced-sausage samples were set as individual $10 \mathrm{~g}$ portions in polyethylene bags for exogenous contamination with Salmonella Typhimurium. Cultures were centrifuged in a Sorvall ST 16 centrifuge (Thermo Fisher, GER) at 5,580 $\times g$ for $10 \mathrm{~min}$ at $4^{\circ} \mathrm{C}$. The cell pellets were resuspended in $0.1 \%$ casein peptone (SigmaAldrich $^{\circledR}$, Germany), in order to obtain two different inoculant levels, $10^{8} \mathrm{CFU} / \mathrm{ml}$ and $10^{6} \mathrm{CFU} / \mathrm{ml}$. Concerning the $10^{8} \mathrm{CFU} / \mathrm{ml}$ inoculum, cells from the overnight culture were suspended in $2 \mathrm{~mL}$ of the peptone solution. For the $10^{6} \mathrm{CFU} / \mathrm{ml}$ inoculum, the harvest cells from the overnight culture were suspended in $10 \mathrm{~mL}$ of a peptone solution and were serially diluted. When the proper dilution was achieved, the cells were harvested by centrifugation and then resuspended in $2 \mathrm{~mL}$ of fresh peptone solution. Two distinct inocula were used to achieve the same cell concentration on the sausages prior to UV-C treatment, due to the extent of pathogen inactivation caused by the $24 \mathrm{~h}$ habituation on the fermented-sausage matrix. 
Cell habituation was performed by exposing $S$. Typhimurium cells to sausage matrices for $24 \mathrm{~h}$ at $25 \pm 1^{\circ} \mathrm{C}$ prior to the $\mathrm{UV}-\mathrm{C}$ treatment, an experimental condition already proven to induce $S$. Typhimurium resistance against simulated gastric fluid, confirming the enhancement of bacteria cells to adverse physical conditions (Mutz et al., 2019).

A $100 \mu \mathrm{L}$ aliquot of the cell suspensions, corresponding to $10^{8} \mathrm{CFU} / \mathrm{ml}$ of $S$. Typhimurium in samples to be subjected to prior sausage habituation and $10^{6} \mathrm{CFU} / \mathrm{ml}$ in samples not subjected to habituation, were spot-inoculated and spread on each side of the sausage slices using a sterile, bent glass rod. The exogenously contaminated sliced sausages were then airdried in a laminar flow and vacuum-sealed (AP450 vacuum sealer, TECMAQ, Brazil). Sliced samples that did not undergo the habituation period were determined to be at $4.28 \pm 0.17 \mathrm{log}$ $\mathrm{CFU} / \mathrm{g}$, while samples subjected to a $24 \mathrm{~h}$ habituation period were determined to be at $4.10 \pm 0.07 \mathrm{CFU} / \mathrm{g}$. Student's $T$ test applied to the initial counts showed no difference in number of cells between both inocula $(p<0.05)$.

The absence of Salmonella spp. in dry-fermented sausage samples prior to exogenous contamination was confirmed by $\mathrm{HE}$ agar plating.

\section{Application of UV-C Light}

The UV-C light emitting equipment comprised six 30 watts UVC lamps interposed by six 55 Wwatt UV-C lamps (OSRAM HNS, OFR, Munich, Deutschland), as designed by Lazaro et al. (2014). Lamps were warmed-up prior to treatments to stabilize $\mathrm{UV}-\mathrm{C}$ radiation intensity $\left(1.53 \pm 0.07 \mathrm{~mW} / \mathrm{cm}^{2}\right)$, monitored by a MRUR-203 UV radiometer (Instrutherm Instrumentos de Medição Ltda, SP, Brazil) placed inside the equipment, where the detector was sealed in the same vacuum package used for the sausage slices. Individual sausage slice packages were placed in the center of the UV-C equipment, $14 \mathrm{~cm}$ distant from the $\mathrm{UV}-\mathrm{C}$ lamps. The sausage slices were exposed to UV-C radiation at increasing time periods $(0,0.3,0.8,1.1,3.3,5.7,12.4$, and $17.0 \mathrm{~min}$ ), set to achieve $0.03,0.10,0.30,0.50,1.10$ to $1.50 \mathrm{~J} / \mathrm{cm}^{2}$ doses. Doses were calculated as $\mathrm{E}=\mathrm{I} \times \mathrm{t}$, where $\mathrm{E}$ is the dose (energy density) in $\mathrm{J} / \mathrm{cm}^{2}, \mathrm{I}$ is intensity in $\mathrm{mW} / \mathrm{cm}^{2}$ and $\mathrm{t}$ is the time in min. UV-C lamp intensities were monitored every $5 \mathrm{~s}$ until each of the seven desired doses were achieved.

\section{Salmonella Typhimurium Enumeration}

After each treatment, $10 \mathrm{~g}$ of the treated samples were aseptically collected and homogenized in a digital stomacher (YK Tecnologia, RS, Brazil) containing $90 \mathrm{~mL}$ of $0.1 \%$ peptone solution. Decimal serial dilutions of the homogenate ranging from 10 - to 1000 -fold were plated on $\mathrm{HE}$ agar plates and incubated at $37 \pm 1^{\circ} \mathrm{C}$ for $24-48 \mathrm{~h}$ in order to estimate cell survival, expressed as $\log \mathrm{CFU} / \mathrm{g}$.

\section{Salmonella Typhimurium Inactivation Kinetics}

To describe the UV-C inactivation kinetics of $S$. Typhimurium habituated to dry-fermented sausage matrices, data following the UV-C treatments were used to fit three distinct survival models.
Models were adjusted by the GInaFIT version 1.6 software (Katholieke Universiteit Leuven, Belgium), a Microsoft ${ }^{\circledR}$ Excel freeware (Geeraerd et al., 2005).

(1) Log-Linear Bigelow (Bigelow and Esty, 1920):

$$
\log _{10}\left(N_{t}\right)=\log _{10}\left(N_{0}\right)-\left(\frac{t}{D}\right)
$$

where $N_{0}$ is the inoculum (log CFU/g), $N_{t}$ is the number of survivals cells $(\log \mathrm{CFU} / \mathrm{g}$ ) at the time $t(\mathrm{~min})$, and $D$ is the decimal reduction time, which is the time under UV-C treatment required to obtain a $1 \log _{10}$ population reduction and $t$ is the UVC dose.

(2) Geeraerd-tail model (Geeraerd et al., 2000)

$$
\begin{aligned}
\log _{10}\left(N_{t}\right)= & \log _{10}\left(10^{\log _{10}(N(0))}-10^{\log 10\left(N_{r e s}\right)}\right) . \\
& \exp e^{-k_{\max } t}+10^{\log _{10}\left(N_{r e s}\right)}
\end{aligned}
$$

where $N_{0}, N_{(t)}$ and $t$ are the same as described above, $N_{\text {res }}$ is the $\mathrm{UV}-\mathrm{C}$ resistant population and $k_{\max T}$ is the maximum specific inactivation dose $\left(\mathrm{J} / \mathrm{cm}^{2}\right)^{-1}$.

(3) Weibull model (Mafart et al., 2002)

$$
\log _{10}\left(N_{t}\right)=\log _{10}\left(N_{0}\right)-\left(\frac{t}{\delta}\right)^{p}
$$

where $N_{0}, N_{(t)}$ and $t$ are the same as described above, $\delta$ is the time required for the first $\log _{10}$ population reduction and $p$ is a shape parameter, where $p>1$ indicates an upward concavity and $p<1$, a downward concavity.

The goodness-of-fit of the tested models was assessed through the adjusted coefficient of determination $\left(R^{2}\right.$ adj $)$ and mean square error (MSE).

\section{Physicochemical Analyses}

Instrumental color parameters were determined according to the CIE color scale using a portable CM-600D spectrophotometer (Konica Minolta Sensing Inc., Osaka, Japan) equipped with an illuminant $\mathrm{A}, 8 \mathrm{~mm}$ aperture, and $10^{\circ}$ standard observer (Monteiro et al., 2017). Lightness $\left(L^{*}\right)$ and redness $\left(a^{*}\right)$ were determined, and the total color difference $(\Delta \mathrm{E})$ between dryfermented sausages treated by UV-C light and non-treated sausages was calculated according to Silveira et al. (2018). In addition, surface reflectance at $650 / 570 \mathrm{~nm}$ was measured to estimate cured meat fading (American Meat Science Association [AMSA], 2012). All data were obtained using the Spectra Magic NX version 2.70 software (Konica Minolta Inc.).

Lipid oxidation was evaluated by the thiobarbituric acidreactive substance (TBARS) method described by Yin et al. (1993) with modifications (Joseph et al., 2012). Absorbances at $532 \mathrm{~nm}$ were determined using a UV-1800 spectrophotometer (Shimadzu Co., Kyoto, Japan). Results were presented as $\mathrm{mg}$ malondialdehyde/kg of dry-cured meat according to a standard curve.

\section{Statistical Analyses}

All microbiological and physicochemical analyses were conducted by assessing three independent biological replicates, 
followed by analytical duplicates. Data concerning UV-C radiation effects on sausage physicochemical properties were evaluated by a stepwise regression analysis using the XLSTAT software, version 2019.1.1 (Addinsoft $^{\circledR}$ ). The $F$-test was used to check model adequacy and parameter significance $(p<0.05)$.

\section{RESULTS}

\section{Model Goodness-of-Fit Assessments and Salmonella Typhimurium UV-C Inactivation Aspects}

Model performance parameters are presented in Table $\mathbf{1}$. The variance explained by the models ranged from 0.73 to 0.98. The Weibull model displayed the higher $R^{2}$ adj and the lowest MSE values for the habituated and non-habituated inactivation. Taken together, the overall evaluation indicates that the Weibull is the best model to describe $S$. Typhimurium UV$\mathrm{C}$ inactivation of both habituated and non-habituated cells, thus being adopted herein.

Inactivation curves for habituated and non-habituated cells presented a positive parameter $p$ shape, indicating upward concavities for the inactivation curves (Figure 1 and Table 1). A reduced inactivation rate, tending toward an asymptote, also known as the inactivation tail, was also observed toward the longest UV-C radiation exposure times in both habituated and non- habituated cells.

\section{Effects of Dry-Fermented Sausage Habituation on Salmonella Typhimurium UV-C Resistance}

As previously pointed out, the survival curves were constructed by counting the survival cells in each treatment time up to $16.9 \mathrm{~min}$, converted to doses of up to $15\left(\mathrm{~J} / \mathrm{cm}^{2}\right)$. The UV-C treatment time required to achieve the first decimal logarithm reduction ( $\delta$ value) of habituated Salmonella Typhimurium

TABLE 1 | Statistical goodness-of-fit and Weibull model parameters for UV-C Salmonella Typhimurium inactivation in dry-fermented sausages.

\begin{tabular}{llcccc}
\hline $\begin{array}{l}\text { Salmonella } \\
\text { cells status }\end{array}$ & Model & $\delta^{*}$ & $\boldsymbol{p}^{*}$ & $\boldsymbol{R}^{2}{ }{ }^{*}$ j & MSE \\
\hline Non- & Log-Linear & - & - & 0.79 & 0.100 \\
habituated & Log-Linear with & - & - & 0.83 & 0.080 \\
& tail & & & & \\
& Weibull & $2.47 \pm 1.10$ & $0.36 \pm 0.06$ & 0.96 & 0.019 \\
Habituated & Log-Linear & - & - & 0.73 & 0.020 \\
& Log-Linear with & - & - & 0.84 & 0.011 \\
& tail & & & & \\
& Weibull & $34.48 \pm 5.78$ & $0.28 \pm 0.03$ & 0.98 & 0.001
\end{tabular}

*Weibull model parameters; $\delta$ is the time required for the first log population reduction; $p$ is a shape parameter, where $p>1$ indicates an upward concavity and $p<1$, a downward concavity; $R^{2}$ adj is the adjusted coefficient of determination; MSE is the mean squared error. Habituated cells were exposed for $24 \mathrm{~h}$ to the dryfermented sausage matrix. Data were obtained from three independent biological replicates, followed by analytical duplicates.

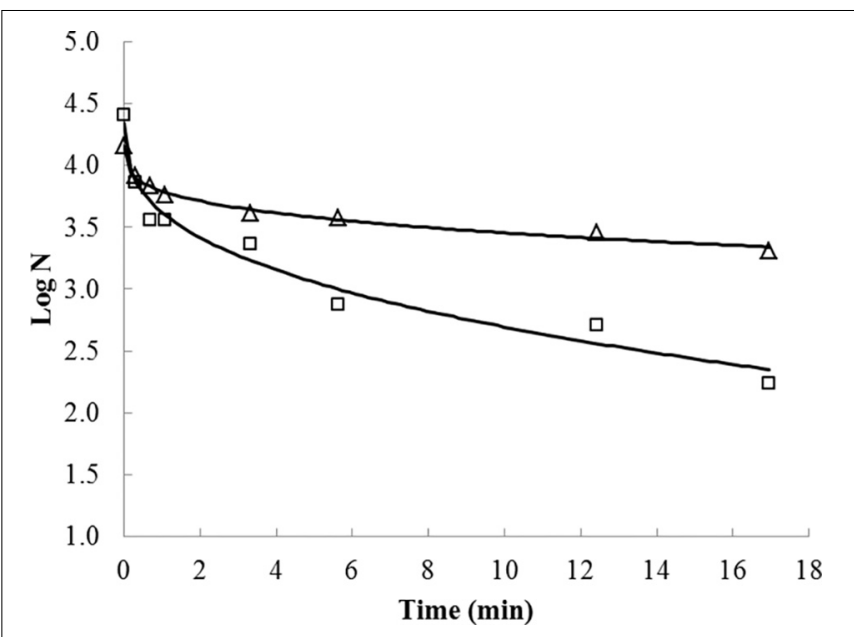

FIGURE 1 | UV-C treatment effects on Salmonella Typhimurium inactivation on dry-fermented sausages. Fitting of the Weibull model (lines) to the observed $S$. Typhimurium inactivation data corresponding to non-habituated (squares) and habituated (triangles) cells exposed to UV-C radiation treatments.

cells was, on average, 14-fold higher than non-habituated cells (Table 1), indicating lower UV-C lethality after the habituation treatment.

\section{Instrumental Color of UV-C Treated Sausages and Lipid Oxidation}

Color parameters, $L^{*}$ (lightness), $a^{*}$ (redness), cured meat fading $(\mathrm{R} 650 / 570)$ and the total color difference $(\Delta \mathrm{E})$ between treated and non-treated sausage slices are displayed in Table 2. UV$\mathrm{C}$ radiation caused sausage lightness values to increase with the treatment time, with the first difference observed at the 5.7 min treatment (Table 2). Redness values presented an overall decrease, and it is noteworthy that $a^{*}$ values began to differ from the control at the lowest time treatment (Table 2). Accompanying redness, the $650 / 570 \mathrm{~nm}$ ratio was found to decrease with increasing UV-C treatments, indicating loss of cured-meat color. Total color changes $(\Delta \mathrm{E})$ were found to increase following UV-C treatment. Malonaldehyde (MDA) contents in sausage samples progressively increased after each UV-C treatment, reaching a maximum concentration of $1.75 \mathrm{mg} / \mathrm{kg}$ after $16.9 \mathrm{~min}$ treatment (Table 2).

\section{DISCUSSION}

\section{Model Goodness-of-Fit Assessments and Salmonella Typhimurium UV-C Inactivation Aspects}

Ultraviolet-C light microbial inactivation is attributed to direct damage at the DNA level by the formation of mutagenic products, mostly cyclobutane-pyrimidine dimers, pyrimidine 64 pyrimidone photoproducts, and their Dewar isomers (Yajima et al., 1995; Bucur et al., 2018). Furthermore, the oxidative effect of UV-C on unsaturated fatty acids from lipids in the food matrix 
TABLE 2 | Instrumental color parameters and lipid oxidation estimated in dry-fermented sausages treated by UV-C radiation.

\begin{tabular}{lcccc}
\hline Treatment time & $\boldsymbol{L}^{*}$ & $\boldsymbol{a}^{*}$ & $\boldsymbol{\Delta} \mathbf{E}$ & TBARS \\
\hline 0.0 & $45.26^{\mathrm{c}, \mathrm{d}}$ & $11.41^{\mathrm{a}}$ & - & $0.23^{\mathrm{h}}$ \\
0.3 & $45.39^{\mathrm{c}, \mathrm{d}}$ & $10.53^{\mathrm{b}}$ & $0.84^{\mathrm{d}}$ & $0.29^{\mathrm{g}}$ \\
0.7 & $45.09^{\mathrm{d}}$ & $10.76^{\mathrm{b}}$ & $1.64^{\mathrm{b}, \mathrm{c}}$ & $0.33^{\mathrm{f}}$ \\
1.1 & $45.51^{\mathrm{c}, \mathrm{d}}$ & $10.90^{\mathrm{b}}$ & $1.49^{\mathrm{c}}$ & $0.38^{\mathrm{e}}$ \\
3.3 & $44.99^{\mathrm{d}}$ & $9.27^{\mathrm{d}}$ & $2.07^{\mathrm{b}}$ & $0.43^{\mathrm{d}}$ \\
5.7 & $45.84^{\mathrm{c}}$ & $10.07^{\mathrm{c}}$ & $2.15^{\mathrm{b}}$ & $0.51^{\mathrm{c}}$ \\
12.4 & $47.05^{\mathrm{b}}$ & $9.13^{\mathrm{d}}$ & $2.06^{\mathrm{b}}$ & $0.97^{\mathrm{b}}$ \\
17.0 & $48.29^{\mathrm{a}}$ & $8.24^{\mathrm{e}}$ & $3.93^{\mathrm{a}}$ & $1.75^{\mathrm{a}}$ \\
\hline
\end{tabular}

$L^{*}$ luminosity; $a^{*}$ redness; $\Delta E$ total color difference when compared to untreated samples; TBARS is expressed as $\mathrm{mg}$ of MDA $\mathrm{kg}$; Different letters in the same column indicate differences ( $p<0.05$ ). Results were obtained from three independent replicates followed by analytical duplicates and are expressed as means \pm standard deviation $(n=6)$.

and on microorganism phospholipid bilayer cell membranes lead to the formation of free radicals, which may damage several macromolecules, such as lipids, proteins, and DNA (Rastogi et al., 2010). The extent of DNA damage by UV-C light is proportional to the amount of light exposure and the efficiency of cell repair mechanisms. However, the overall effect does not necessarily imply in a linear relationship between dose and inactivation, as noted in the death curves reported herein.

Several decontamination methods studies have reported deviations from a first order kinetic of death, including the tails commonly found in UV-C inactivation curves (Coroller et al., 2006; Chun et al., 2009; Souza and Fernández, 2011; Condón-abanto et al., 2016). The Weibull model better described the survival of habituated and non-habituated S. Typhimurium cells, as expected due to the concave survival curves observed herein present study. The Weibull model presented the highest $R^{2}$ and the lowest MSE, indicating lower discrepancy between experimental and fitted values among the models tested herein (Granato et al., 2014).

One of the postulated hypotheses regarding the inactivation curve tailing effect is based on the heterogeneity of the cell population (Cerf, 1977), which implicates in an intrinsic dissimilarity in the resistance of each single cell against abiotic stress conditions and conservation technologies (Aspridou and Koutsoumanis, 2015). Furthermore, Coroller et al. (2006) pointed out subgroupings within the microbial population, translating this dissimilarity into resistant and susceptible sub-populations (Coroller et al., 2006). Applying the aforementioned hypotheses to the data reported herein, it is possible to infer that the sharp inactivation kinetic observed following short UV-C treatment can be considered as the death of the susceptible $S$. Typhimurium sub-population. On the other hand, the tail found during longer treatments may represent an UV-C treatment under-effect on the resistant sub-population.

An alternative hypothesis for the tailing effect in microorganism inactivation attributes the non-linearity of the inactivation curves to treatment failure in reaching target microorganisms within the food matrix (Cerf, 1977). This, in turn, can be attributed to the low penetration power of UV-C radiation (Koutchma, 2009) and its inactivation effectiveness dependence on treatment parameters and food surface characteristics (Gayán et al., 2011). Both hypotheses should be taken into account concerning the observed inactivation tail, since the variable UV-C sensitivity of subpopulations reflected as non-regular effectiveness through food matrices surfaces must be managed in order to achieve meat product safety and preservation.

\section{Effects of Dry-Fermented Sausage Habituation on Salmonella Typhimurium UV-C Resistance}

Chun et al. (2009) reported a $2 \log \mathrm{CFU} / \mathrm{g}$ reduction in nonhabituated $S$. Typhimurium cells in ready-to-eat ham after exposure to UV-C light at $0.8 \mathrm{~J} / \mathrm{cm}^{2}$, a higher inactivation than described herein. The aforementioned study detected higher $S$. Typhimurium inactivation in the matrix, however, it should be noted that the bacteria was not subjected to any matrix habituation. It should be emphasized that the efficiency of UV$\mathrm{C}$ against non-habituated cells can be an overestimation of the real efficiency of the decontamination treatment.

In the present study, habituated $S$. Typhimurium cells were 14-fold more resistant against UV-C treatment than nonhabituated cells. This implies in the fact that $S$. Typhimurium pre-exposed to the sausage matrix and its environmental stressful conditions are less sensitive to UV-C treatment, impacting UV-C decontamination efficacy.

The results described herein can be attributed to at least two hypotheses. First, the sub-lethal stresses caused by the meat matrix inherent physiochemical characteristics, such as low water activity and moderate acidic $\mathrm{pH}$, may trigger a general cell stress response through alternative sigma factors, $\operatorname{RpoE}\left(\sigma^{\mathrm{E}}\right)$ and $\mathrm{RpoS}$ $\left(\sigma^{S}\right)$, leading to stress cross-protection and acquired tolerance against distinct stresses (Mutz et al., 2020). Indeed, increased UV-C tolerance in $S$. Typhimurium cells previously adapted to abiotic stresses have been reported (Gruzdev et al., 2011; Estilo and Gabriel, 2017). High osmolarity is known to increase $\sigma^{\mathrm{E}}$ levels, and the regulon of this general sigma factor also responds to envelope, and oxidative stresses (McMeechan et al., 2007). $\sigma^{S}$, also induced by low osmolarity and/or acid stresses, is known to regulate set of enzymes involved in oxidative damage protections and DNA repair (such as catalases and exonucleases) (Eisenstark et al., 1996). Together, these pre-adaptations can elicit a more efficient response against the damage provoked by the UV-C treatment. Corroborating the hypothesis that habituated cells may acquire resistance against UV-C, Bucheli-Witschel et al. (2010) observed that E. coli mutants lacking RpoS, are more susceptible to UV-C radiation than wild-type strains (BucheliWitschel et al., 2010). There is, however, still a need to elucidate the molecular mechanisms behind the relationship exerted by abiotic stresses inherent to fermented sausages characteristics and the resulting UV-C resistance. Further research on gene expression by meta-transcriptomics, similar to those reported in studies dealing with other abiotic stressors (Gruzdev et al., 2012; Jia et al., 2017), and even for pulsed UV-light exposure (in Listeria monocytogenes) (Uesugi et al., 2016) are encouraged, in order to understand the metabolic pathways and cellular processes impacted by UV-C in S. Typhimurium. 
Secondly, pathogen internalization into the sausage matrix should also be taken into account (Lim and Harrison, 2016), since the random penetration of bacteria in the dry-cured matrix is known to play a role in impairing UV-C treatment effectiveness (likewise for pulsed UV light) (Rajkovic et al., 2017). Taken together, these two possibilities may lead to the inference that, in order to estimate the real effectiveness of the UV-C decontamination treatment, the effects of pathogen habituation to the stressful conditions within the dry-cured meat matrix should be assessed, in order to mimic the adverse scenario which foodborne pathogens undergo in dry-fermented meat matrices.

\section{Instrumental Color and Lipid Oxidation}

Color is the first quality attribute perceived by consumers when evaluating meat products, used as a synonym for their quality, directly influencing purchase intentions and, therefore, of the utmost importance. Lightness increases in UV-C treated meat are usually associated to protein denaturation, as myoglobin content is inversely related to $L^{*}$ values (Canto et al., 2016, 2018; Cunha et al., 2018). Furthermore, UV-C can also induce the denaturation of sarcoplasmic and myofibrillar proteins, leading to exposure of hydrophobic groups and increased free water content, altering meat surface reflectance (Canto et al., 2018). Decreased $a^{*}$ values are correlated with the heme pigment oxidation process. UV-C light is a well-known oxidizing agent, therefore displaying the ability to affect meat color, as changes in protein conformation or in redox state alters the hemo-chrome of this matrix (Sun et al., 2009). Nytrosil-hemochrome present in cured meats, similar to myoglobin in fresh ones, is sensitive to light exposure and oxidative reactions, which leads to fading in cured products (Suman and Joseph, 2013).

The collective increase in lightness and decrease in meat redness are responsible for dry-cured meat discoloration (Wambura and Verghese, 2011; Ganan et al., 2013). The curedmeat discoloration process is reinforced by the absorbance ratio $650 / 570 \mathrm{~nm}$ that describes cured-meat fading, which decreases with UV-C treatment (American Meat Science Association [AMSA], 2012). The total color changes observed in UV-C treated sausages followed an increasing trend for redness $\left(a^{*}\right)$ and lightness $\left(L^{*}\right)$ with increasing UV-C treatment time/intensity (Table 2). In order to obtain a tangible estimation of the extent of color changes $(\Delta E)$, an $\Delta E$ value of 5 units can be adopted as the threshold for easy food color change perception (Tazrart et al., 2016; do Rosário et al., 2017; Canto et al., 2018). Thus, applying the aforementioned reference to $\Delta \mathrm{E}$ data, although the total color difference in sausage slices increased, no perceptive change should be observed.

Another undesirable effect of UV-C treatment is lipid oxidation, as it results in loss of nutritional value and the development of a rancid off-flavor perceived by consumers when the amount of MDA in treated-meat reaches a threshold of $2 \mathrm{mg}$ of $\mathrm{MDA} / \mathrm{kg}$ meat (Campo et al., 2006). UV-C radiation is an oxidant agent that promotes free radical formation, increasing lipid oxidation even in low-moisture meat matrices (Barden and Decker, 2013; Monteiro et al., 2018). The MDA content observed herein increased throughout the UV-C treatment period, corroborating the observed color changes in the same dose range. This simultaneous change in TBARS and color parameters may result from meat pigment oxidation, as the reactive intermediates formed by the UV-C treatment are capable of enhancing lipid oxidation (Faustman et al., 2010). However, it is noteworthy to mention that the sausage samples did not reach the aforementioned MDA limit, even at the highest treatment time, which reinforces no harmful effect on product acceptance.

\section{CONCLUSION}

The Weibull model fitted UV-C Salmonella Typhimurium inactivation behavior. The inactivation curve presented an upward concavity following by an inactivation tail toward high treatment time/intensity, indicating a natural heterogeneity within the $S$. Typhimurium population toward UV-C susceptibility. Habituation of $S$. Typhimurium cells to the fermented sausage matrix lead to a 14 -fold increase in pathogen resistance against UV-C treatment. This undermined UV-C efficacy has practical consequences, as the establishment of effective doses based on non-habituated cells will lead to UV-C treatment efficacy overestimations. The physicochemical changes in dry-fermented sausages in the experimental conditions did not point to major product quality deteriorations. However, increases in treatment time/intensity to meet the inactivation of one logarithm decimal reduction of habituated $S$. Typhimurium, herein estimated at $34 \mathrm{~min}$, may compromise food quality and its acceptance.

The approach of treatment efficacy assessments using habituated pathogens is encouraged in order to evaluate the UV-C decontamination methodology in a more critical perspective concerning decontamination effectiveness and food quality preservation and acceptance. Furthermore, future metatranscriptomics studies are encouraged, to unveil the cellular mechanisms behind the relationship between stress responses and increased UV-C resistance.

\section{DATA AVAILABILITY STATEMENT}

The datasets generated for this study are available on request to the corresponding author.

\section{AUTHOR CONTRIBUTIONS}

YM and DR contributed to conceptualization, methodology, validation, formal analysis, investigation, data curation, and original draft preparation. $\mathrm{PB}, \mathrm{CC}-\mathrm{J}$, and VP were responsible for the resources, reviewing and editing the manuscript. CC-J and VP supervised the study. CC-J was responsible for the funding acquisition.

\section{FUNDING}

The authors would like to thank the financial support provided by the Fundação Carlos Chagas Filho de Amparo à Pesquisa do 
Estado do Rio de Janeiro (FAPERJ), grants E-26/203.049/2017 E-26/202.815/2018 - E-26/202.428/2018 and Conselho Nacional de Desenvolvimento Científico e Tecnológico (CNPq), grant 311422/2016-0, and Coordenação de Aperfeiçoamento de Pessoal de Nível Superior - Brasil (CAPES) Finance Code 001.

\section{REFERENCES}

American Meat Science Association [AMSA] (2012). AMSA Meat Color Measurement Guidelines. Savoy, IL: AMSA.

Andreoli, G., Merla, C., Valle, C. D., Corpus, F., Morganti, M., D'incau, M., et al. (2017). Foodborne Salmonellosis in Italy: Characterization of Salmonella enterica serovar Typhimurium and monophasic variant 4,[5], 12:i-isolated from salami and human patients. J. Food Prot. 80, 632-639. doi: 10.4315/0362-028X. JFP-16-331

Aspridou, Z., and Koutsoumanis, K. P. (2015). Individual cell heterogeneity as variability source in population dynamics of microbial inactivation. Food Microbiol. 45, 216-221. doi: 10.1016/j.fm.2014.04.008

Barden, L., and Decker, E. A. (2013). Lipid oxidation in low-moisture food: a review. Crit. Rev. Food Sci. Nutr. 56, 2467-2482. doi: 10.1080/10408398.2013. 848833

Bigelow, W. D., and Esty, J. R. (1920). The thermal death point in relation to time of typical thermophilic organisms. J. Infect. Dis. 27, 602-617. doi: 10.1093/infdis/ 27.6.602

Bonardi, S., Bruini, I., Bolzoni, L., Cozzolino, P., Pierantoni, M., Brindani, F., et al. (2017). Assessment of Salmonella survival in dry-cured Italian salami. Int. J. Food Microbiol. 262, 99-106. doi: 10.1016/j.ijfoodmicro.2017.09.016

Bucheli-Witschel, M., Bassin, C., and Egli, T. (2010). UV-C inactivation in Escherichia coli is affected by growth conditions preceding irradiation, in particular by the specific growth rate. J. Appl. Microbiol. 109, 1733-1744. doi: $10.1111 /$ j.1365-2672.2010.04802.x

Bucur, F. I., Grigore-Gurgu, L., Crauwels, P., Riedel, C. U., and Nicolau, A. I. (2018). Resistance of Listeria monocytogenes to stress conditions encountered in food and food processing environments. Front. Microbiol. 9:2700. doi: 10. 3389/fmicb.2018.02700

Cabeza, M. C., de la Hoz, L., Velasco, R., Cambero, M. I, and Ordóńez, J. A. (2009). Safety and quality of ready-to-eat dry fermented sausages subjected to E-beam radiation. Meat Sci. 8, 320-327. doi: 10.1016/j.meatsci.2009.05.019

Campo, M. M., Nute, G. R., Hughes, S. I., Enser, M., Wood, J. D., and Richardson, R. I. (2006). Meat flavour perception of oxidation in beef. Meat Sci. 72, 303-311. doi: 10.1016/j.meatsci.2005.07.015

Canto, A. C. V. C. S., Costa-Lima, B. R. C., Suman, S. P., Monteiro, M. L. G., Viana, F. M., Salim, A. P. A. A., et al. (2016). Color attributes and oxidative stability of longissimus lumborum and psoas major muscles from Nellore bulls. Meat Sci. 121, 19-26. doi: 10.1016/j.meatsci.2016.05.015

Canto, A. C. V. C. S., Monteiro, M., lucia, G., Costa-Lima, B. R. C., Lazaro, C. A., Marsico, E. T., et al. (2018). Effect of UV-C radiation on Salmonella spp. reduction and oxidative stability of caiman (Caiman crocodilus yacare) meat.J. Food Saf. 39:e12604. doi: 10.1111/jfs.12604

Castro, V. S., Rosario, D. K. A., Mutz, Y. S., Paletta, A. C. C., Figueiredo, E. E. S., and Conte-Junior, C. A. (2019). Modelling inactivation of wild-type and clinical Escherichia coli O26 strains using UV-C and thermal treatment and subsequent persistence in simulated gastric fluid. J. Appl. Microbiol. 127, 1564-1575. doi: 10.1111/jam.14397

Center for Disease Control and Prevention [CDC] (2019). Surveillance for Foodborne Disease Outbreaks United States, 2017: Annual Report. Atlanta, GA: CDC.

Cerf, O. (1977). Tailing of survival curves of bacterial spores. J. Appl Bacteriol. 42, 1-19. doi: 10.1111/j.1365-2672.1977.tb00665.x

Chun, H., Kim, J., Chung, K., Won, M., and Bin, K. (2009). Inactivation kinetics of listeria monocytogenes, Salmonella enterica serovar Typhimurium and Campylobacter jejuni in ready-to-eat sliced ham using UV-C irradiation. Meat Sci. 83, 599-603. doi: 10.1016/j.meatsci.2009.07.007

Condón-abanto, S., Condón, S., Raso, J., Lyng, J. G., and Álvarez, I. (2016). Inactivation of Salmonella Typhimurium and Lactobacillus plantarum by UV-C

\section{ACKNOWLEDGMENTS}

The authors would like to thank the National Institute for Quality Health Control (INCQS) of the Oswaldo Cruz Foundation (FIOCRUZ) for providing the Salmonella Typhimurium ATCC 14028 strain used in this study.

light in flour powder. Innov. Food Sci. Emerg. Technol. 35, 1-8. doi: 10.1016/j. ifset.2016.03.008

Coroller, L., Leguerinel, I., Mettler, E., Savy, N., Mafart, P., and Boissie, L. (2006). General model, based on two mixed Weibull distributions of bacterial resistance, for describing various shapes of inactivation curves. Appl. Environ. Microbiol. 72, 6493-6502. doi: 10.1128/AEM.00876-06

Cunha, L. C. M., Monteiro, M. L. G., Costa-lima, B. R. C., Guedes-oliveira, J. M., Alves, V. H. M., Almeida, A. L., et al. (2018). Effect of microencapsulated extract of pitaya (Hylocereus costaricensis) peel on color, texture and oxidative stability of refrigerated ground pork patties submitted to high pressure processing. Innov. Food Sci. Emerg. Technol. 49, 136-145. doi: 10.1016/j.ifset.2018.08.009

do Rosário, D. K. A., da Silva Mutz, Y., Peixoto, J. M. C., Oliveira, S. B. S., de Carvalho, R. V., Carneiro, J. C. S., et al. (2017). Ultrasound improves chemical reduction of natural contaminant microbiota and Salmonella enterica subsp. enterica on strawberries. Intern. J. Food Microbio. 241, 23-29. doi: 10.1016/j. ijfoodmicro.2016.10.009

Eisenstark, A., Calcutt, M. J., Becker-Hapak, M., and Ivanova, A. (1996). Role of Escherichia coli rpoS and associated genes in defense against oxidative damage. Free Radic. Biol. Med. 21, 975-993. doi: 10.1016/S0891-5849(96)00154-2

Estilo, E. E. C., and Gabriel, A. A. (2017). Previous stress exposures influence subsequent UV-C resistance of Salmonella enterica in coconut liquid endosperm. LWT Food Sci. Technol. 86, 139-147. doi: 10.1016/j.lwt.2017.07.061

European Food Safety Authority [EFSA] and European Centre for Disease Prevention, and Control [ECDC] (2019). The European Union one health 2018 zoonoses report. EFSA J. 17:e05926. doi: 10.2903/j.efsa.2019.5926

Faustman, C., Sun, Q., Mancini, R., and Suman, S. P. (2010). Myoglobin and lipid oxidation interactions: mechanistic bases and control. Meat Sci. 86, 86-94. doi: 10.1016/j.meatsci.2010.04.025

Ferrari, R. G., Rosario, D. K., Cunha-Neto, A., Mano, S. B., Figueiredo, E. E., and Conte-Junior, C. A. (2019). Worldwide epidemiology of Salmonella serovars in animal-based foods: a meta-analysis. Appl. Environ. Microbiol 85, e00591-19. doi: 10.1128/AEM.00591-19

Ganan, M., Hierro, E., Hospital, X. F., Barroso, E., and Fernández, M. (2013). Use of pulsed light to increase the safety of ready-to-eat cured meat products. Food Control 32, 512-517. doi: 10.1016/j.foodcont.2013.01.022

Gayán, E., Monfort, S., Álvarez, I., and Condón, S. (2011). UV-C inactivation of Escherichia coli at different temperatures. Innov. Food Sci. Emerg. Technol. 12, 531-541. doi: 10.1016/j.ifset.2011.07.008

Geeraerd, A. H., Herremans, C. H., and Van Impe, , J. F. (2000). Structural model requirements to describe microbial inactivation during a mild heat treatment. Int. J. Food Microbiol. 59, 185-209. doi: 10.1016/S0168-1605(00)00362-7

Geeraerd, A. H., Valdramidis, V. P., and Van Impe, J. F. (2005). GInaFiT, a freeware tool to assess non-log-linear microbial survivor curves. Int. J. Food Microbiol. 102, 95-105. doi: 10.1016/j.ijfoodmicro.2004.11.038

Geveke, D. J., Boyd, G., and Zhang, H. Q. (2011). UV penetration depth in liquid egg white and liquid whole egg. J. Food Process. Preservat. 757, 754-757. doi: 10.1111/j.1745-4549.2011.00525.x

Gossner, C. M., Van Cauteren, D., Le Hello, S., Weill, F. X., Terrien, E., Tessier, S., et al. (2012). Nationwide outbreak of Salmonella enterica serotype 4,[5], 12: i:-infection associated with consumption of dried pork sausage, France, November to December 2011. Euro Surveill. 17:20071. doi: 10.2807/ese.17.05. 20071-en

Granato, D., de Araújo Calado, V. M., and Jarvis, B. (2014). Observations on the use of statistical methods in food science and technology. Food Res. Int. 55, 137-149. doi: 10.1016/j.foodres.2013.10.024

Gruzdev, N., McClelland, M., Porwollik, S., Ofaim, S., Pinto, R., and SaldingerSela, S. (2012). Global transcriptional analysis of dehydrated Salmonella enterica serovar Typhimurium. Appl. Environ. Microbiol. 78, 7866-7875. doi: 10.1128/ AEM.01822-12 
Gruzdev, N., Pinto, R., and Sela, S. (2011). Effect of desiccation on tolerance of Salmonella enterica to multiple stresses. Appl. and Environ. Microbiol. 77, 1667-1673. doi: 10.1128/AEM.02156-10

Jia, K., Wang, G., Liang, L., Wang, M., Wang, H., and Xu, X. (2017). Preliminary transcriptome analysis of mature biofilm and planktonic cells of Salmonella Enteritidis exposure to acid stress. Front. Microbiol. 8:1861. doi: 10.3389/fmicb. 2017.01861

Joseph, P., Suman, S. P., Rentfrow, G., Li, S., and Beach, C. M. (2012). Proteomics of muscle-specific beef color stability. J. Agri. Food Chem. 60, 3196-3203. doi: $10.1021 /$ jf204188v

Koutchma, T. (2009). Advances in ultraviolet light technology for non-thermal processing of liquid foods. Food Bioprocess Technol. 2, 138-155. doi: 10.1007/ s11947-008-0178-3

Lazaro, C. A., Monteiro, M. L. G., Canto, A. C. V. S., Mano, S. B., and Franco, R. M. (2014). Effects of ultraviolet light on biogenic amines and other quality indicators of chicken meat during refrigerated storage. Poult. Sci. 93, 23042313. doi: 10.3382/ps.2013-03642

Leistner, L., and Gorris, L. G. M. (1995). Food preservation by hurdle technology. Trends Food Sci. Technol. 6, 41-46. doi: 10.1016/S0924-2244(00)88941-4

Lim, W., and Harrison, M. A. (2016). Effectiveness of UV light as a means to reduce Salmonella contamination on tomatoes and food contact surfaces. Food Control 66, 166-173. doi: 10.1016/j.foodcont.2016.01.043

Mafart, P., Couvert, O., Gaillard, S., and Leguerinel, I. (2002). On calculating sterility in thermal preservation methods: application of the Weibull frequency distribution model. Int. J. Food Microbiol. 72, 107-113. doi: 10.1016/S01681605(01)00624-9

McMeechan, A., Roberts, M., Cogan, T. A., Jørgensen, F., Stevenson, A., Lewis, C., et al. (2007). Role of the alternative sigma factors $\sigma \mathrm{E}$ and $\sigma \mathrm{S}$ in survival of Salmonella enterica serovar Typhimurium during starvation, refrigeration and osmotic shock. Microbiol 153, 263-269. doi: 10.1099/mic.0.29235-0

Monteiro, M. L. G., Mársico, E. T., Canto, A. C. V. D. C., Costa-Lima, B. R. D., Costa, M. P. D., Viana, F. M., et al. (2017). Impact of UV-C light on the fatty acid profile and oxidative stability of Nile tilapia (Oreochromis niloticus) fillets. J. Food Sci. 82, 1028-1036. doi: 10.1111/1750-3841.13685

Monteiro, M. L. G., Mársico, E. T., Mano, S. B., Alvares, S., Rosenthal, A., Lemos, M., et al. (2018). Combined effect of high hydrostatic pressure and ultraviolet radiation on quality parameters of refrigerated vacuum-packed tilapia (Oreochromis niloticus) fillets. Sci. Rep. 8:9524. doi: 10.1038/s41598-01827861-9

Mutz, Y. D. S., Rosario, D. K. A., Paschoalin, V. M. F., and Conte-Junior, C. A. (2020). Salmonella enterica: a hidden risk for dry-cured meat consumption? Crit. Rev. Food Sci. Nutr. 60, 976-990. doi: 10.1080/10408398.2018.1555132

Mutz, Y. S., Rosario, D. K., Castro, V. S., Bernardes, P. C., Paschoalin, V. M., and Conte-Junior, C. A. (2019). Prior exposure to dry-cured meat promotes resistance to simulated gastric fluid in Salmonella Typhimurium. Foods 8:603. doi: $10.3390 /$ foods 8120603

Porto-Fett, A. C. S., Call, J. E., Shoyer, B. E., Hill, D. E., Pshebniski, C., Cocoma, G. J., et al. (2010). Evaluation of fermentation, drying, and/or high pressure processing on viability of Listeria monocytogenes, Escherichia coli O157:H7, Salmonella spp. and Trichinella spiralis in raw pork and Genoa salami. Int. J. Food Microbiol. 140, 61-75. doi: 10.1016/j.ijfoodmicro.2010.02.008

Rajkovic, A., Tomasevic, I., De Meulenaer, B., and Devlieghere, F. (2017). The effect of pulsed UV light on Escherichia coli O157: H7, Listeria monocytogenes, Salmonella Typhimurium, Staphylococcus aureus and staphylococcal enterotoxin A on sliced fermented salami and its chemical quality. Food Control 73, 829-837. doi: 10.1016/j.foodcont.2016.09.029
Rastogi, R. P., Kumar, A., Tyagi, M. B., and Sinha, R. P. (2010). Molecular mechanisms of ultraviolet radiation-induced DNA damage and repair. J. Nucleic Acids 2010, 592980. doi: 10.4061/2010/592980

Rosario, D. K., Bernardo, Y. A., Mutz, Y. S., Tiwari, B., Rajkovic, A., Bernardes, P. C., et al. (2019). Modelling inactivation of Staphylococcus spp. on sliced Brazilian dry-cured loin with thermosonication and peracetic acid combined treatment. Intern. J. Food Microbiol. 309, 108328. doi: 10.1016/j.ijfoodmicro. 2019.108328

Scavia, G., Ciaravino, G., Luzzi, I., Lenglet, A., Ricci, A., Barco, L., et al. (2013). A multistate epidemic outbreak of Salmonella Goldcoast infection in humans, June 2009 to March 2010: the investigation in Italy. Euro. Surveill. 18:20424. doi: 10.2807/ese.18.11.20424-en

Silveira, L. O., do Rosário, D. K. A., Giori, A. C. G., Oliveira, S. B. S., da Silva Mutz, Y., Marques, C. S., et al. (2018). Combination of peracetic acid and ultrasound reduces Salmonella Typhimurium on fresh lettuce (Lactuca sativa L. var. crispa). J. Food Sci. Technol. 55, 1535-1540. doi: 10.1007/s13197-018-3071-8

Souza, P. M., and Fernández, A. (2011). Effects of UV-C on physicochemical quality attributes and Salmonella Enteritidis inactivation in liquid egg products. Food Control 22, 1385-1392. doi: 10.1016/j.foodcont.2011. 02.017

Suman, S. P., and Joseph, P. (2013). Myoglobin chemistry and meat color. Annu. Rev. Food Sci. Technol. 4, 79-99. doi: 10.1146/annurev-food-030212-182623

Sun, W. Q., Zhou, G. H., Xu, X. L., and Peng, Z. Q. (2009). Studies on the structure and oxidation properties of extracted cooked cured meat pigment by four spectra. Food Chem. 115, 596-601. doi: 10.1016/j.foodchem.2008. 12.060

Tazrart, K., Zaidi, F., Lamacchia, C., and Haros, M. (2016). Effect of durum wheat semolina substitution with broad bean flour (Vicia faba) on the Maccheronccini pasta quality. European Food Res. Technol. 242, 477-485. doi: 10.1007/s00217015-2558-z

Uesugi, A. R., Hsu, L. C., Worobo, R. W., and Moraru, C. I. (2016). Gene expression analysis for Listeria monocytogenes following exposure to pulsed light and continuous ultraviolet light treatments. LWT Food Sci. Technol. 68, 579-588. doi: 10.1016/j.lwt.2016.01.007

Wambura, P., and Verghese, M. (2011). Effect of pulsed ultraviolet light on quality of sliced ham. LWT Food Sci. Technol. 44, 2173-2179. doi: 10.1016/j.lwt.2011. 05.016

Yajima, H., Takao, M., Yasuhira, S., Zhao, J. H., Ishii, C., Inoue, H., et al. (1995). A eukaryotic gene encoding an endonuclease that specifically repairs DNA damaged by ultraviolet light. The EMBO J. 14, 2393-2399. doi: 10.1002/j.14602075.1995.tb07234.x

Yin, M. C., Faustman, C., Riesen, J. W., and Williams, S. N. (1993). $\alpha$-Tocopherol and ascorbate delay oxymyoglobin phospholipid oxidation in vitro. J. Food Sci. 58, 1273-1276. doi: 10.1111/j.1365-2621.1993.tb06164.x

Conflict of Interest: The authors declare that the research was conducted in the absence of any commercial or financial relationships that could be construed as a potential conflict of interest.

Copyright (C) 2020 Mutz, Rosario, Bernardes, Paschoalin and Conte-Junior. This is an open-access article distributed under the terms of the Creative Commons Attribution License (CC BY). The use, distribution or reproduction in other forums is permitted, provided the original author(s) and the copyright owner(s) are credited and that the original publication in this journal is cited, in accordance with accepted academic practice. No use, distribution or reproduction is permitted which does not comply with these terms. 